\title{
ASYMPTOTICS OF GENERALIZED VALUE DISTRIBUTION FOR HERGLOTZ FUNCTIONS
}

\author{
Y. CHRISTODOULIDES
}

Abstract. Estimates of limiting value distributions for boundary values of Herglotz functions are extended to allow the possibility of value distributions with respect to measures other than Lebesgue measure. We establish a relation between the generalized theory of value distribution and the angle subtended at a point in the upper half-plane, and we carry out an analysis of the corresponding composed Herglotz functions and their measures. The results are applicable to a description of boundary behaviour for the Weyl $m$-function in Sturm-Liouville theory.

Mathematics subject classification (2010): 30D35, 34M30.

Keywords and phrases: Asymptotic generalized value distribution, Herglotz functions.

\section{REFERENCES}

[1] N. I. Akhiezer And I. M. Glazman, Theory of Linear Operators in Hilbert space I, Pitman, London, 1981.

[2] S. V. Breimesser, J. D. E. Grant, And D. B. Pearson, Value distribution and spectral theory of Schrödinger operators with $L^{2}$-sparse potentials, J. Comput. Appl. Math. 148 (2002), 307-322.

[3] S. V. Breimesser And D. B. Pearson, Asymptotic value distribution for solutions of the Schrödinger equation, Math. Phys. Anal. Geom. 3 (4) (2000), 385-403.

[4] Y. T. Christodoulides, Asymptotic generalized value distribution of solutions of the Schrödinger equation, Oper. Matrices 8 (1) (2014), 279-285.

[5] Y. T. Christodoulides And D. B. Pearson, Generalized value distribution for Herglotz functions and spectral theory, Math. Phys. Anal. Geom. 7 (4) (2004), 309-331.

[6] Y. T. Christodoulides And D. B. PeArson, Spectral theory of Herglotz functions and their compositions, Math. Phys. Anal. Geom. 7 (4) (2004), 333-345.

[7] E. A. Coddington And N. Levinson, Theory of Ordinary Differential Equations, McGraw-Hill, New York, 1955.

[8] R. DEL Rio, S. Jitomirs Kaya, Y. LAST, AND B. Simon, Operators with singular continuous spectrum. IV. Hausdorff dimensions, rank one perturbations, and localization, J. Anal. Math. 69 (1996), 153-200.

[9] R. Del Rio And O. TChebotaReVA, Sturm-Liouville operators in the half-axis with local perturbations, J. Math. Anal. Appl. 329 (2007), 557-566.

[10] F. Gesztesy and A. MaKarov, $S L(2, \mathbb{C})$, exponential Herglotz representations, and spectral averaging, S. Petersburg Math. J. 15 (2004), 393-418.

[11] G. Herglotz, Über potenzreihen mit positivem, reelem Teil in Einheitskreis, Sächs. acad. Wiss. Leipzig 63 (1911), 501-511.

[12] C. A. MarX, Continuity of spectral averaging, P. Am. Math. Soc. 139 (1) (2010), 283-291.

[13] D. B. Pearson, Value distribution and spectral theory, P. Lond. Math. Soc. 68 (3) (1994), 127-144.

[14] D. B. Pearson, Quantum Scattering and Spectral Theory, Academic Press, London, 1988. 